Revue d'histoire de l'Amérique française

सQA REVUE D.HISTOIRE DE L'AMÉRIQUE FRANÇAISE

\title{
Histoire, sciences humaines et culture au Québec (1955-1970)
}

\section{Yvan Lamonde}

Volume 25, numéro 1, juin 1971

URI : https://id.erudit.org/iderudit/303046ar

DOI : https://doi.org/10.7202/303046ar

Aller au sommaire du numéro

Éditeur(s)

Institut d'histoire de l'Amérique française

ISSN

0035-2357 (imprimé)

1492-1383 (numérique)

Découvrir la revue

Citer cette note

Lamonde, Y. (1971). Histoire, sciences humaines et culture au Québec (1955-1970). Revue d'histoire de l'Amérique française, 25(1), 106-113.

https://doi.org/10.7202/303046ar d'utilisation que vous pouvez consulter en ligne.

https://apropos.erudit.org/fr/usagers/politique-dutilisation/ 
NOTE CRITIQUE

\section{HISTOIRE, SCIENCES HUMAINES ET CULTURE AU QUÉBEC (1955-1970)}

\section{Yvan LAMONDE \\ Québec}

\section{Emergence de l'histoire culturelle}

Divers signes et événements permettent de situer autour des années 1950 l'émergence d'une conscience culturelle nouvelle et d'une problématique d'histoire culturelle explicitement élaborée. Dès 1939, S. Marion explore les influences littéraires françaises au Québec, suivi dans cette voie par M. Trudel qui, au même moment de l'apparition de l'histoire au niveau universitaire et de la célébration du Centenaire de l'Histoire de Garneau, publie son Voltaire (1945). Gérard Morisset lance dès 1942 sa collection Champlain sur les arts traditionnels, encouragé dans ce domaine par R. Traquair et M. Gagnon. Les folkloristes avaient parié sur notre originalité culturelle en promouvant la création en 1944 des Archives de Folklore. La nomination en 1949 de la Commission Massey sur les arts, les lettres et les sciences au Canada n'aurait-elle pas justement porté au plan politique des aspirations et des convictions nouvelles? Il faut enfin mentionner la parution en 1954 de l'Histoire littéraire de l'Amérique française d'Auguste Viatte qui aiguilla sur de nouvelles voies l'histoire littéraire.

Les hommes qui vers 1955 précisèrent la problématique d'une histoire culturelle du Canada français sur la lancée de laquelle nous sommes encore pour une bonne part empruntèrent à la tradition d'une autre génération un certain nombre d'interrogations. M. Wade, P. Sylvain, C. Galarneau reprirent en les enrichissant les questions de Marion, Viatte, Trudel et autres ${ }^{1}$.

1 A propos de la bibliographie des historiens mentionnés dans la présente note de recherche, voir Y. Lamonde, "Bibliographie des bibliographies des historiens du Québec", Recherches Sociographiques, XII (1971) et plus particulièrement F.E.L. Priestley et R. M. Wiles, The Humanities in Canada (Toronto, 1964), avec Supplément (Toronto, 1966) : 208-236 et 133-165. Compléter avec Livres et auteurs canadiens (1961), Répertoire des thèses en cours portant sur des sujets d'histoire et autres sujets connexes (1966), la bibliographie de la RHAF (1967-) et Recherche et littérature canadienne-française (Ottawa, 1969).

RHAF, vol. 25, no 1 (juin 1971) 


\section{Problématique}

Alors que M. Wade décrivait une problématique culturelle axée sur les relations entre le Canada français et le Canada anglais et entre le Canada français et ses sources européennes (Paris, Rome, Londres) de 1760 jusqu'à 1940 avec une attention particulière aux fluctuations du nationalisme ${ }^{2}$, C. Galarneau, familier avec les préoccupations du groupe des Annales, orientait ses recherches vers l'histoire des mentalités ou de la psychologie collective entendue au sens de Halbwachs, Blondel, Febvre, Dupront, Duby et Mandrou ${ }^{3}$, tandis que Roland Lamontagne s'intéressait, comme Braudel, à la civilisation atlantique ${ }^{4}$. Cet intérêt à une histoire culturelle davantage consciente de ses objectifs et de ses méthodes coïncida avec l'essor des sciences humaines au Québec et surtout avec un renouveau des études historiques sur le XIX ${ }^{\mathrm{e}}$ siècle québécois ${ }^{5}$.

L'inventaire des aspects d'histoire culturelle qui attirèrent d'abord les chercheurs indique clairement la fécondité de ce renouveau des recherches sur le $\mathrm{XIX}^{\mathbf{e}}$ siècle.

\section{Domaines de recherches}

Les échanges culturels franco-canadiens polarisent plusieurs chercheurs autour de problèmes différents: les effets de la Révolution ${ }^{6}$, les échanges d'idées et d'objets, l'antagonisme

$2 \mathrm{M}$. Wade, "The Culture of French-Canada", The Culture of Contemporary Canada, ed. by J. Park (Ithaca, 1957), 367-395; "An introduction to French-Canadian Intellectual History", French-Canadian Thinkers of the nineteenth and twentieth Centuries, ed. by. L. Lapierre (Montreal, 1966), 9-22. Voir aussi M. Brunet "Trois dominantes de la pensée canadiennefrançaise: l'agriculturisme, l'anti-étatisme et le messianisme", La présence anglaise et les Canadiens (Montréal, 1958), 113-166.

3 C. Galarneau, "Histoire de l'Europe et histoire du Canada. Esquisse pour une histoire de la mentalité religieuse au Canada", Société Historique du Canada. Rapport (1956): 26-37; "Commentaire", Situation de la recherche sur le Canada français (Québec, 1963), 273-275; "Toile de fond: histoire de la mentalité et des idées", Histoire de la littérature française du Québec, éd. par P. de Grandpré (Montréal, 1967), I: 34-42; "Histoire culturelle", RHAF, 24, 3 (1970) : 479-480.

4 Roland Lamontagne, Aperçu structural du Canada au XVIIIe siècle (Montréal, 1964) ; L'Atlantique jusqu'au temps de Maurepas, Aspects de géohistoire dw Canada (Montréal, 1965); Civilisation: concepts et faits (Montréal, 1966).

5 Situation de la recherche . . . op. cit.: passim.

${ }^{6}$ C. Galarneau, La France devant l'opinion canadienne (1760-1815) (Québec, 1970), bibliographie. A propos du Canada devant l'opinion française, voir les articles de A. Yon, RHAF (1964). 
ultramontain-libéral ${ }^{7}$ où la biographie historique a joué jusqu'à maintenant un rôle primordial (Bourget, Tardivel, Buies, Papineau, Dessaulles, Dorion, Raymond...), les relations diplomatiques avec la France ${ }^{8}$, les relations de voyages ${ }^{9}$. Ces domaines de recherches appellent bien sûr une analyse de la réception et de la transformation au Québec de ces apports. D'où ces travaux sur l'imprimerie, la librairie, les bibliothèques ${ }^{10}$, sur la presse, les journaux et les revues à tendances idéologiques ${ }^{11}$, sur les sociétés culturelles ${ }^{12}$.

Le renouvellement méthodologique de l'historiographie récente en même temps que son orientation vers le XIX ${ }^{e}$ siècle ont sans doute permis une distance critique des historiens face à leurs prédécesseurs et déclenché une série d'études sur l'historiographie québécoise ${ }^{13}$. Ce domaine de recherche s'avère particulièrement riche en possibilités: psychanalyse et sociologie

${ }^{7} \mathrm{P}$. Savard, "Note sur l'étude de l'ultramontanisme au Canada français", Rapport de la Société Canadienne d'Histoire de l'Eglise catholique, (RSCHEC), (1966) : 13-15; P. Sylvain, "Quelques aspects de l'antagonisme libéral-ultramontain au Canada français", Recherches Sociographiques, (RS), VIII, 3 (1967) : 275-297; J.-P. Bernard, La pensée et l'influence des Rouges (1848-1867) (Ph. D., U. de Montréal, 1968); J. Costisella, L'esprit révolutionnaire dans la littérature canadienne-française (Montréal, 1968); à propos d'un courant plus récent, voir A. Fauteux, Bibliographie de la question universitaire Laval-Montréal (1852-1921) (Montréal, 1922) et les articles de G. Lavallée dans RHAF (1958-1959).

$8 \mathrm{P}$. Savard, Le Consulat général de France à Québec et à Montréal de 1859 à 1914 (Québec, 1970).

$9 \mathrm{~J}$. Hare, Les Canadiens francais aux quatre coins $d u$ monde: une bibliographie commentée des récits de voyages, 1670-1914 (Québec, 1964); P. Savard, "Le journal de l'abbé Benjamin Paquet, étudiant à Rome, 18631866”, Culture, 26 (1965) : 64-83.

${ }^{10} \mathrm{~A}$. Drolet, Les bibliothèques canadiennes 1604-1960 (Montréal, 1965). - P. Savard, "La bibliothèque du Chevalier Clément Vincelette", RSCHEC (1965) : 79-90; J. Hare et J.-P. Wallot, Les imprimés dans le Bas-Canada 1801-1810 (Montréal, 1967), bibliographie, XIV-XXIII.

$11 \mathrm{~J}$. Hamelin et A. Beaulieu, Les journaux du Québec de 1764 à 1964 (Québec, 1965), bibliographie; Y. Tessier, "Ludger Duvernay et les débuts de la presse périodique aux Trois-Rivières", RHAF, XVIII, 3 (1964) : 387-404; 4 (1965) : 566-81, 624-627; E. Lavoie, "La clientèle du Courrier du Canada", Culture, XXX, 4 (1969): 299-309; XXXI, 1 (1970): 40-57; "Les idéologies au Canada français, 1850-1900", RS, X, 2-3 (1969).

12 V. Morin, "Clubs et sociétés notoires d'autrefois", Cahiers des Dix $(1948,1949,1950,1951)$. - P. Savard, "Le Cercle Catholique de Québec, 1876-1897", Culture, XXVIII, 1 (1967) : 3-17. - J.-R. Rioux, L'Institut Canadien. Les débuts de l'Institut Canadien et du journal "l'Avenir" 18441849. Thèse de Maîtrise (Laval, 1967).

${ }^{13} \mathrm{Y}$. Lamonde, "Bibliographie des bibliographies des historiens du Québec”, RS, XII (1971). 
d'une discipline, zone d'émergence privilégiée de la conscience historique ${ }^{14}$...

Dans la mesure où le présent survol des travaux en histoire culturelle départage les recherches selon qu'elles témoignent d'une intention analytique et interprétative ou d'une intention descriptive et dans la mesure où la relance de l'histoire culturelle a coïncidé avec le développement de la sociologie, il faut tout de suite, pour comprendre l'orientation actuelle des recherches, faire place aux études de macro-sociologie, dispersées çà et là depuis 1960 dans Recherches Sociographiques ${ }^{15}$. La macrosociologie a assuré l'entreprise d'études nombreuses sur les idéologies au Canada français, mettant quelquefois l'accent sur des perspectives de sociologie de la connaissance ${ }^{16}$.

Comme l'attestent les nombreuses monographies et la diversité des thèses en cours, l'éducation retient l'attention des chercheurs ${ }^{17}$. Instance importante de la formation des mentalités, l'éducation commande plus d'une approche: histoire d'une institution, de son personnel, de la provenance et de la destination sociales de ses élèves, histoire d'une discipline d'enseignement, d'un courant d'idée (gaumisme...)... Il faut noter toutefois que malgré les travaux de L.-P. Audet, l'instruction primaire et la formation technique, agricole, commerciale ou autre accusent, au plan des monographies, d'importantes lacunes ${ }^{18}$.

14 F. Dumont, "Idéologie et savoir historique", Cahiers internationaux de sociologie, 35 (1963) : 43-60; "Idéologie et conscience historique dans la société canadienne-française du XIXe siècle", France et Canada français du $X V I^{e}$ au $X X^{e}$ siècle (Québec, 1966), 269-290.

15 F. Dumont, "L'étude systématique de la société globale canadiennefrançaise", Situation de la recherche sur le Canada français, op. cit., 277292.

$16 \mathrm{~L}$. Chevrette et Y. Lamonde, "Bibliographie des travaux sur les idéologies au Québec" (à paraître dans Les idéologies au Canada français, 1900-1929) ; sur l'orientation de ces travaux, voir F. Dumont, "Note sur l'analyse des idéologies", RS, IV, 2 (1963): 155-167; voir aussi Les idées politiques des premiers ministres du Canada (Ottawa, 1968).

17 R. S. Harris et A. Tremblay, Bibliographie de l'enseignement supérieur au Canada (Québec-Toronto, 1960); Supplément (1965); C. Galarneau, "Recherches sur l'histoire de l'enseignement classique au Canada français", RHAF, XX (1966): 18-27; M. Lebel, P. Savard, R. Vézina, Aspects de l'enseignement au Petit Séminaire de Québec (1765-1945) (Québec, 1968) ; A. Labarrère-Paulé, Les instituteurs laïques au Canada français 1836-1900 (Québec, 1965) et Les lä̈ques et la presse pédagogique au Canada français au XIXe siècle (Québec, 1963); J.-J. Jalois, J.-F. Perrault (1753-1844) et les origines de l'enseignement lä̈que au Bas Canada (Montréal, 1969).

18 R. Rumilly, Histoire de l'Ecole des Hautes Etudes Commeiciales de Montréal (Montréal, 1966). 
Plus que l'histoire des idées et des "institutions" culturelles, les phénomènes de mentalité prêtent à des échanges avec l'histoire sociale à laquelle on coïncidera facilement une priorité qui ne soit pas impérialiste. L'esclavage, la criminalité, la sorcellerie, la tempérance, les épidémies, les phénomènes de marginalité sociale (folie, prostitution...) ont déjà fait l'objet d'études valables ou en cours ${ }^{19}$. De même pour l'histoire des professions ${ }^{20}$ et du monde ouvrier.

Depuis quinze ans, l'histoire des sciences a connu un renouveau attendu. Après les travaux d'Antoine Roy, de Huard sur Provencher, de Vallée sur Sarrazin, l'histoire des sciences a jusqu'à maintenant privilégié quelques secteurs: la contribution canadienne à la botanique du XVIIe siècle ${ }^{21}$, la trame scientifique générale de l'histoire canadienne avec des insistances sur J.-B. Meilleur, Marie-Victorin et quelques autres personnages ou phénomènes ${ }^{22}$, l'histoire de la médecine ${ }^{23}$. Le peu de travaux en histoire des techniques ${ }^{24}$ prive l'histoire des mentalités de connaissances intéressantes sur les phénomènes de résistance aux innovations techniques, sur la détention de brevets par des Canadiens français...

Sollicitée par l'histoire sociale et économique, l'histoire culturelle commence à chercher ailleurs que chez les élites les signes

19 M. Trudel, L'esclavage au Canada français (Montréal, 1960); R. Boyer, Les crimes et les châtiments au Canada français du XVIIe au $X X^{e}$ siècle (Montréal, 1966); A. Lachance, Le bourreau au Canada sous le Régime français (Québec, 1966); R.-L. Séguin, La sorcellerie au Canada français du XVIIe au XXe siècle (Montréal, 1961). 1962).

20 A. Vachon, Histoire du notariat canadien, 1621-1960 (Québec,

21 Voir la contribution de C. de Bonnault, M. Raymond et J. Rousseau à Les botanistes français en Amérique du Nord avant 1850 (Paris, 1957); les travaux de R. Lamontagne sur La Galissonière (1962), Pierre Bouguer (1964), Chabert de Cogolin (1964); J.-C. Dubé, Claude-Thomas Dupuy intendant de la Nouvelle-France, 1678-1738 (Montréal, 1969) ; Pierre Boucher, Histoire véritable et naturelle... (Boucherville, 1964): texte et études; E. Mitchell, Messire Pierre Boucher, seigneur de Boucherville, 1622-1717 (Boucherville, 1967).

22 L. Lortie, "Les débuts de l'ère scientifique", Aux sources $d u$ présent (Toronto, 1960), 90-104; "La trame scientifique de l'histoire du Canada", Pionniers de la science canadienne, éd. par G. F. G. Stanley (Toronto, 1966), 3-35; C. Ouellet, La vie des sciences au Canada français (Québec, 1964); L.-P. Audet, Le Frère Marie-Victorin. Ses idées pédagogiques (Québec, 1942 ) ; R. Rumilly, Le Frère Marie-Victorin et son temps (Montréal, 1949). 23 Trois siècles de médecine québécoise (Québec, 1971).

24 Voir par exemple les travaux de R.-L. Séguin et particulièrement "L'équipement aratoire prémachiniste aux XVIIe, XVIII" et XXe siècles", France et Canada, . . op. cit., 121-138. 
d'une vie culturelle originale. Capable d'innover en histoire de la culture populaire, soit en s'attardant à des documents (almanachs, feuilletons...) et à des phénomènes nouveaux, soit en spécifiant un concept de culture adapté au Québec contemporain et à la contre-culture ${ }^{25}$, l'histoire culturelle a tout intérêt à exploiter davantage les documents et les travaux de folklore ${ }^{26}$. Si le folklore pose à l'historien de nouvelles questions sur le passé culturel, l'ethnographie ou l'anthropologie culturelle du Québec lui ouvre tout un champ d'exploration, que ce soit celui des isolats de la Côte-Nord ${ }^{27}$ ou celui des communautés rurales ou en passe d'urbanisation ${ }^{28}$. En plus de relancer l'histoire culturelle contemporaine du Québec, de telles explorations interdisciplinaires risquent de renouveler les problématiques parfois saturées de certaines sciences humaines au Québec.

Des échanges fructueux commencent à s'établir entre l'ethnohistoire et l'anthropologie amérindienne autour des phénomènes de rencontres de cultures et de symboliques collectives ${ }^{29}$.

25 P. Bélanger et P. Paquet, "La crise de la culture dans la société québécoise", Le Devoir (30 déc. 1970), A-23; Culture vivante (1966).

26 Archives de folklore (1946); L. Lacourcière, "Les études de folklore français au Canada", Culture, VI (1945): 3-9; "The Present State of French Canadian Folklore Studies", Journal of American Folklore, 74, 294 (oct.-déc. 1961) : 373-382; "L'étude de la culture: le folklore", Situation de la recherche, op. cit., 253-262; "La tradition orale au Canada", France et Canada... op. cit., 223-231.

27 M.-A. Tremblay, "L'ethnographie de la Côte-Nord du Saint-Laurent", RS, VIII, 1 (1967): 81-87; voir aussi le numéro spécial de RS (XI, 3, 1970) sur les Iles-de-la-Madeleine; M.-A. Tremblay, Les changements socio-culturels à Saint-Augustin (Québec, 1969).

28 Autour du débat sur les travaux de L. Gérin, H. Miner, E. Hughes et de la thèse de la "folk-society", voir $P$. Garigue, "Mythes et réalités dans l'étude du Canada francais", Contributions à l'étude des sciences de l'homme, 3 (1956) : 123-132; "Change and continuity in rural FrenchCanada", Culture, 18 (1957): 379-392; M. Rioux, "Sur le développement socio-culturel du Canada français", Contributions à l'étude . . 4 (1959) : 144-162 et d'autres indications dans P. Garigue, Bibliographie du Québec (1955-1965) (Montréal, 1967).

29 Voir les travaux de $M$. Barbeau et J. Rousseau, particulièrement: "Le Canada aborigène dans le contexte historique", RHAF, XVIII, 1 (1964): 39-63; les contributions diverses à Anthropologica (1955); les articles de Rémi Savard dans Interprétation (vol. 3 et 4, 1969-1970) et le Bulletin d'information Recherches Amérindiennes au Québec (1971-); du côté historique, la thèse de Donald Smith, French Canadian Historians' Images of the Indian in the "heroic period" of New France, 1534-1663. Thèse de maîtrise. (U. Laval, 1969), J. F. McDermott, "Etudes récentes sur l'histoire culturelle du pays des Illinois, 1930-1955 (RHAF, IX, 4, 1956) : 512-522. 
Toujours dans la perspective d'échanges de documents et d'interrogation entre l'histoire socioculturelle et d'autres sciences humaines, il faut mentionner deux terrains de recherche à sonder : l'ethnologie juridique ${ }^{30}$ et la linguistique ${ }^{31}$.

Un chercheur isolé mérite mention en raison de sa contribution, avant 1955, à l'histoire intellectuelle de Montréal, Mgr O. Maurault ${ }^{32}$.

Il eût fallu consacrer plus d'attention aux arts (peinture, orfèvrerie, architecture, sculpture, mobilier, cinéma, musique, artisanat...), mais l'état des travaux, à quelques exceptions près, indique les lacunes analytiques et interprétatives de ces recherches historiques.

\section{Aspects critiques}

A travers tous ces écrits, il est difficile de repérer un concept unifié, si non convergent, d'histoire culturelle et d'histoire culturelle du Québec. On ne connaît pas de tentative de définition $\mathrm{du}$ domaine et de la méthode de l'histoire culturelle dont la Kulturgeschichte en Allemagne, l'histoire des idées (Mornet, Trénard) et l'histoire des mentalités (Dupront, Mandrou, Tudescq) en France, l'histoire des idées (à la F. Boas qui fonda le Journal of History of Ideas) ou l'histoire "intellectuelle" (Higham, Skotheim) aux Etats-Unis pourraient servir de pôle de comparaison. Quant au concept de culture du Québec, il n'a pas été dégagé explicitement des travaux québécois. La majorité de ceux-ci décrirait la culture par ses manifestations diverses (éducation, idées, légendes, voyages ...) et malgré quelques tentatives interprétatives ponctuelles a négligé cette possible perspective de totalité de la culture. Les travaux sur l'historiographie et sur les idéologies, par leur perspective plus cri-

${ }^{30}$ R. Boult, Bibliographie du droit canadien (Montréal, 1966); H. Lamaute, Sociologie des mours et du droit au Québec (Paris, Doctorat 1969).

31 Etudes sur le parler français aw Canada (Québec, 1955); G.-R. Lefebvre, "L'étude de la culture: la linguistique", Situation de la recherche... op. cit., 233-249. G. Dulong, Bibliographie linguistique du Canada français (Québec-Paris, 1966); K. Fillion, "Essai sur l'évolution du mot habitant (XVIIe-XVIII' siècles)", RHAF, 24, 3 (1970) : 375-401.

32 O. Maurault, "Montreal Intellectual 1642-1942", Moisson de VilleMarie (Montréal, 1942), 121-150; "Montréal intellectuel", Bulletin des Etudes françaises (mai 1942): 104-107; "La vie intellectuelle au temps de Garneau", Centenaire de l'Histoire du Canada de F.-X. Garneau (Montréal, 1945), 55-70; "Montréal, ville intellectuelle, artistique et musicale", Culture, XII (1951) : 356-372. 
tique, insistent finalement beaucoup sur la culture définie comme "projet collectif" totalisant, auquel les historiens, parmi d'autres, ont fourni une expression au niveau de la conscience historique. L'intérêt des sociologues à ces questions n'est pas sans rapport avec l'effort interprétatif fourni dans ces recherches. Enfin les travaux en anthropologie ou en ethnologie ont exploité davantage les persistances et les changements socio-culturels; Miner et Hughes ont posé le problème de l'urbanisation d'un Québec rural et de l'impact de cette évolution sur la culture traditionnelle (mours, croyances,...). L'élaboration sommaire du domaine et du cadre théorique d'analyse de la culture du Québec semble aller de pair avec la carence interprétative, "explicative" de nombreux travaux en histoire culturelle.

Cette carence interprétative tient à deux facteurs principaux: les difficultés d'un traitement social de la culture et, comme pour l'histoire générale du Québec, la rupture entre le passé et le présent, ce qui signifie ici, pour l'historien à tout le moins, d'assumer l'apparition d'une culture de masse et de revoir l'évolution de la culture québécoise en fonction de cette nouvelle position culturelle. Socialement, en raison de l'accent mis sur la culture savante (imprimé, éducation ...) nous connaissons mieux l'univers de groupes sociaux limités. Malgré une richesse documentaire exceptionnelle, les folkloristes et ethnographes tardent encore à nous faire connaître cette culture populaire essentielle ici. A fortiori, est-il évident que nous ne savons rien de cette culture populaire urbaine des débuts de l'industrialisation, remaniée par les mass media et les loisirs.

Cet inventaire des chercheurs, des travaux et des domaines de l'histoire culturelle du Québec constitue, dans un premier mouvement, la mise en place d'éléments dont la dispersion pouvait empêcher un aménagement de la recherche. Le repérage des problématiques accule à un dépassement: la recherche d'une convergence méthodologique possible de toutes ces interrogations sur la culture du Québec. 